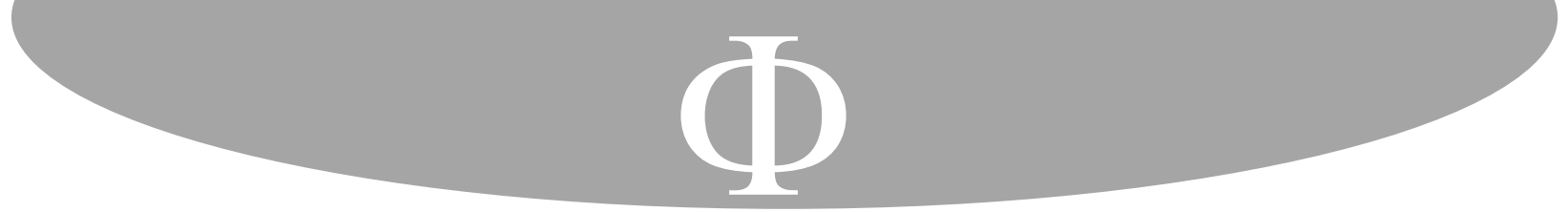

\title{
Aproximación al problema de Dios en Zubiri
}

\section{(1) (2)}

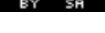

José Alfonso Villa Sánchez*

Universidad Michoacana de San Nicolás de Hidalgo

Morelia, México

Para citar este artículo: Villa Sánchez, José Alfonso. «Aproximación al problema de Dios en Zubiri».

Franciscanum 175, Vol. 63 (2021): 1-32.

\section{Resumen}

Bajo la hipótesis de que la realidad humana y la realidad divina conforman una sola estructura circular, este estudio recorre algunos de los hitos de la filosofía primera de Xavier Zubiri para mostrar que, efectivamente, el hombre en tanto realidad humana, constitutivamente religada al poder de lo real como su fundamento último y posibilitante, tiene una dimensión teologal, no teológica, en la que se ofrece con claridad y evidencia que Dios es un problema para el hombre, es decir, que este está lanzado inexorablemente, en su propia vida, hacia ese problema y que el decurso de esa vida es, en realidad, la resolución de ese problema.

\section{Palabras clave}

Filosofía de la religión, fenomenología de la religión, el problema de Dios, la realidad fundamental, religación.

\section{Approach to God's problem in Zubiri}

\begin{abstract}
Based on the hypothesis human reality and divine reality constitute a single circular structure, the present study explores some of the pillars of Xavier Zubiri's first philosophy, aimed to show that certainly man, as a human reality, is constitutively linked to the power of reality as its final and empowering principle, within a non-theological, dimension, which clearly and evidently states that God is a problem for man, that is, that he is inexorably thrown, in his own life, towards that problem and that the course of that life is, in fact, the resolution of the problem itself.
\end{abstract}

\footnotetext{
* Doctor en Filosofía por la Universidad Iberoamericana (Ciudad de México). Profesor Investigador en el Insituto de Investigaciones Filosóficas de la Universidad Michoacana de San Nicolás de Hidalgo (Morelia, Michoacán, México). Miembro del Sistema Nacional de Investigadores del Consejo Nacional de Ciencia y Tecnología de México. Miembro del Círculo Latinoamericano de Fenomenología. Contacto: alphonsovilla@hotmail.com. ORCID: https://orcid.org/0000-0002-3254-0613.
} 


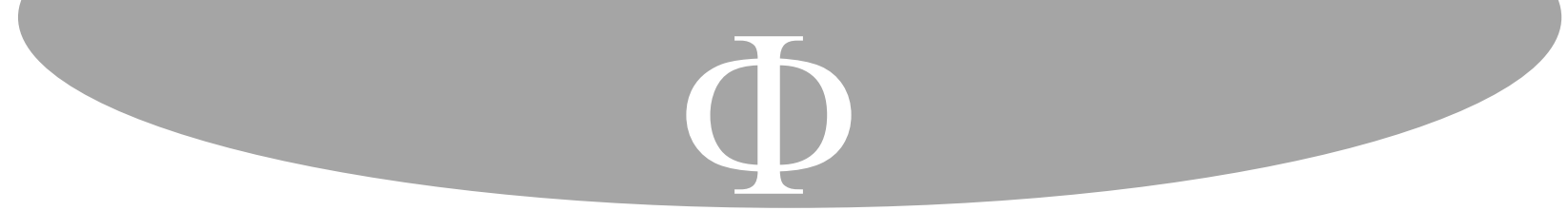

el hombre de hoy se siente vertido desde el transcurso de su vida hacia lo radical de su realidad ${ }^{13}$.

Ya que los dioses han huido, o ya que han sido asesinados; ya que las promesas políticas y sociales de progreso, paz y justicia, parecen no poder cumplirse, el hombre de este siglo se ha visto volcado «hacia lo radical de su realidad», hacia lo que tiene de finitud y de relatividad, así como hacia lo que tiene de absoluto: en esta versión, «la inteligencia va desde las cosas y desde el transcurso de su vida hacia las ultimidades del universo y de sí mismo» ${ }^{14}$. Mostrar que la afirmación constante y tajante de la finitud de la realidad humana -síndrome de una época en la que todas las posturas parecen ser igualmente verdaderas- es testimonio fehaciente de la sed de absoluto de toda realidad, es uno de los propósitos de esta reflexión. Lo que Heidegger dice del habla puede decirse, sin más, sobre la «relación» del hombre con Dios: «Ya caminamos en la región, en el ámbito, que nos concierne» ${ }^{15}$.

¿Cuál es su marco? ¿en qué región de la filosofía debe inscribirse la pregunta sobre la relación de la realidad humana con «el problema de Dios»? La filosofía de la religión, consolidada como tal en las postrimerías de la época moderna ${ }^{16}$, ha tratado de manera indiscriminada los conceptos de religión, Dios, lo divino y lo sagrado. En los propios textos de Zubiri -si exceptuamos el concepto de lo sagrado, que no aparece de manera técnicaoperan deslices de nivelación entre los conceptos de Dios, lo divino y la religión, con las agravantes de sus presupuestos confesionales, monoteístas y cristianos.

La atención científica y filosófica a la religión como un hecho humano, necesitado de estudio, investigación y comprensión -como cualquier otro hecho humano-, ha tenido diversos momentos en el proceso de su consolidación: el estudio de las religiones comparadas, la filosofía de la religión, la fenomenología de la religión, la hermenéutica de las tradiciones, etc. En este universo es en el que se inscribe esta meditación. Pero con sus propios matices. Porque no se ocupa de la religión en sentido general, y mucho menos de una religión en particular. Su objeto de estudio tampoco es Dios, ni en general -algo así como lo divino-, ni en particular -el Dios de alguna religión-. Por lo tanto, tampoco se ocupa de lo sagrado.

Si en algo están de acuerdo, sin embargo, las grandes filosofías que han tenido necesidad de pensar el siglo pasado y el actual es en afirmar la finitud humana, por lo tanto, la finitud de este mundo ${ }^{17}$. Pero los desacuerdos entre estas filosofías están en la manera como piensan la finitud; y en si debe dejársele a ella la última palabra: porque si todo es finito, si

\footnotetext{
${ }^{13}$ Xavier Zubiri, Naturaleza. Historia. Dios, 398.

${ }^{14}$ Xavier Zubiri, Naturaleza. Historia. Dios, 398.

${ }^{15}$ Martin Heidegger, «La esencia del habla», 133.

${ }^{16}$ Solari nos ofrece las fuentes para un resumen «de los inicios de la filosofía de la religión» en la nota número 1 de su profuso estudio. Cf. Enzo Solari, La raíz de lo sagrado. Contribuciones de Zubiri a la filosofía de la religión (Santiago de Chile: UCN-RiLeditores, 2010), 17.

17 Es el caso de la ontología fundamental de Heidegger, del existencialismo de Sartre y Camus, de la hermenéutica de Gadamer y Ricoeur; pero también del estructuralismo y de filosofías como la de Derrida y Nancy.
} 


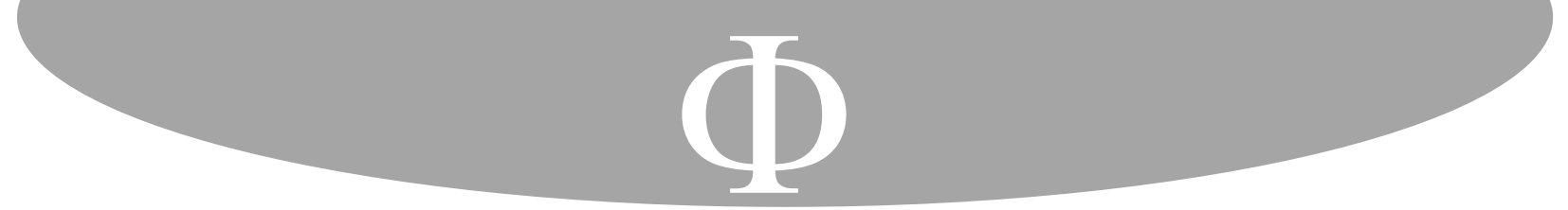

El logos es movimiento, tanto en la primera fase, la de impelencia intelectiva, como en la que le sigue, la de intención intelectiva; pero es un movimiento que, instalado en la cosa real, sin abandonarla, se yergue sobre ella -pero desde ella-; es un movimiento que debe entenderse como emanado desde el interior de la aprehensión primordial de realidad, cuyo trabajo es empujar desde dentro la compacción de la mera formalidad de realidad, para que vaya lentamente abriéndose y ofreciendo su interior, brindando lo que es en realidad. En sus inicios más primigenios, esta fase ve aparecer los incipientes momentos de ese despliegue intelectivo que es el logos, despliegue ausente en la aprehensión primordial.

Una segunda fase en el movimiento del logos viene a completar el despliegue iniciado, en un movimiento en cierto sentido inverso al de la impelencia, pues ahora el logos se mueve del campo hacia la cosa real:

en esa distanciación la cosa real nos retiene tensos en ella, y por consiguiente revertidos a ella en un intentum por la tensión misma de la distancia. Es un movimiento del intentum para inteligir desde el campo lo que la cosa es en realidad. Por tanto es un referirnos desde el campo a la cosa: es intención intelectiva. El intentum se ha tornado en intención. Toma de distancia e intención intelectiva he aquí los dos momentos del movimiento intelectivo. $^{74}$

En la intelección que es el logos, este empieza por erguirse sobre la realidad y desde ella, como si quisiera separársele; pero no lo puede hacer, porque no hay logos puro, sino logos habitado de realidad, logos sentiente ${ }^{75}$. Este querer separarse de lo real - sin poder hacerlo jamás-, trae de regreso al logos hacia lo real -de donde nunca se ha ido-. Pero dado que no es ya el logos que tira hacia fuera, sino el logos que viene del intento de alejarse, se puede decir que ya no es el mismo del momento del erguirse, porque ahora está enriquecido por lo que ha visto y traído desde el campo de realidad: ese enriquecimiento queda condensado en su estar tenso de regreso en relación con aquello sobre lo que se mantiene erguido.

De todas las ideas sobre el logos es preciso destacar de manera señalada la del campo de realidad: de la mera realidad, la intelección que es el logos va hacia lo que la cosa es en realidad, es decir, a su campo de realidad. Pues no hay, en primer lugar, sólo cosas reales, sino siempre cosas reales en su campo de realidad: un libro sobre la mesa, la cual está en el estudio, ubicado en el edificio $x$ de la universidad, etc. ${ }^{76}$ El logos es, pues, la intelección que

\footnotetext{
${ }^{74}$ Xavier Zubiri, Inteligencia y Logos, 80.

75 «El logos es sentiente porque intelige la realidad como la formalidad de ciertos contenidos sentidos. Claro que hay realidades postuladas y construidas, como en las matemáticas y la ficción, pero tal postulación constructiva se apoya en la misma realidad de las cosas que son reales en y por sí mismas. A la vez, el logo es sentiente porque es una intelección que inexorablemente recorre la realidad según la cual quedan los contenidos sentidos: un recorrido en la realidad desde su aprehensión compacta hasta su aprehensión diferencial, dual». Enzo Solari, La raíz de lo sagrado, 836.

${ }^{76}$ En el inicio del segundo capítulo de las Categorías (1 a 16), lo mismo que en el inicio del capítulo cuarto, Aristóteles da cuenta de las dificultades que trae consigo tratar a las cosas como si estuvieran siempre
} 


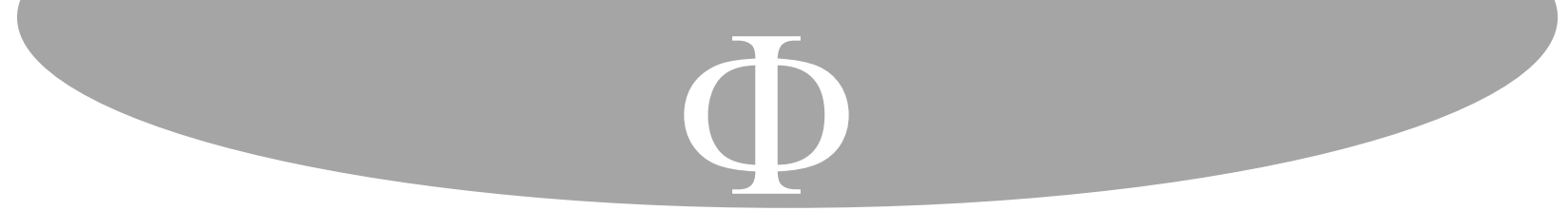

mensura de realidad. Es una búsqueda radical en un mundo abierto en sí mismo. Marcha es abrirse a la insondable riqueza y problematismo de la realidad, no sólo en sus notas propias sino también en sus formas y modos de realidad ${ }^{78}$.

Mientras el logos se mueve en el campo lo que lo que las cosas son en realidad, la razón marcha en la profundidad mundanal de la realidad. Esta es una mera indicación sobre la marcha intelectiva, que de ninguna manera le hace justicia a la exigente exposición de Zubiri en Razón Sentiente.

Debe repararse, finalmente, en que la inteligencia sentiente es una estructura, y no un proceso; de modo que se malentiende la naturaleza de su acto si se piensa que primero hay aprehensión, luego logos, y más tarde razón. Como ejemplo del recubrimiento intelectivo de los tres momentos, puede ponerse la reflexión que ahora mismo estamos llevando a cabo, tratando de comprender qué ha de entenderse por «el problema de Dios»: es una marcha de la razón, montada sobre el movimiento campal del logos, montado a su vez sobre aprehensiones múltiples de cosas reales. Pocas veces, cronológicamente, la intelección empieza por la aprehensión; muchas empiezan por el movimiento del logos, y casi siempre por la marcha de la razón.

Ahora bien, el logos en tanto distanciación intelectiva se dice de muchas maneras, porque las cosas reales en sus contenidos son igualmente de muchas maneras. Una de esas maneras es la del logos teologal. En el marco de la reflexión sobre «el problema de Dios» para el hombre, Zubiri muestra que el logos ha tenido distintos caracteres a lo largo de la historia, y los esquematiza de la siguiente manera' ${ }^{79}$ 1) Logos revelante; 2) Logos teológico, dividido a su vez en kerigmático, ostensivo y científico; este último puede ser especulativo, histórico y hermenéutico; y 3) Logos teologal. Este último, desdoblamiento del mero logos sentiente, es fundamento tanto del logos revelante como del teológico.

¿Cómo es que el logos sentiente torna logos teologal, posibilidad del logos teológico en todos sus modos, y aún del logos revelante cuando lo hay? ¿cuáles son las características de ese logos que permiten mostrar que «la dimensión teologal del hombre no es propia de uno $\mathrm{u}$ otro aspecto del hombre y de su vida, sino que concierne a la totalidad de su ser mismo» ${ }^{80}$, y que por eso «afecta a la vida humana en su plenitud formal y no a fisuras o quiebres de ella» ${ }^{81}$ ? Dios no puede ser primordialmente objeto de un logos que lo reduce a un mero recurso - un ente remedial- para las emergencias de la vida, sea para reclamarle la presencia del mal moral en el mundo o para buscar socorro en momentos aciagos. Porque Dios no es un ente; ni siquiera el Ser Supremo. Es la realidad -así, con esa vaguedad y ambigüedad- compleja y contradictoria de la que emana toda otra realidad, también la humana; en la que se mantienen, y hacia la que marchan, desde la brizna más modesta hasta la inteligencia mejor dotada. No hay ningún encaminarse hacia el futuro que no sea sino una

\footnotetext{
${ }^{78}$ Xavier Zubiri, Inteligencia y Razón, 23-24.

${ }^{79} \mathrm{Cf}$. Xavier Zubiri, El problema teologal del hombre, 6.

${ }^{80}$ Xavier Zubiri, El problema teologal del hombre, 27.

${ }^{81}$ Xavier Zubiri, El problema teologal del hombre, 27.
} 
